\title{
As poéticas do Grupo Bilbao: espazos e cidades
}

\author{
Carmen Mejía Ruiz \\ Universidade Complutense \\ cmejiaru@filol.ucm.es \\ Recibido:agosto de 2012 Aceptado: septiembre de 2012
}

\begin{abstract}
Resumo: Neste artigo se analiza a diversidade e a pluralidade semántica da «cidade» na poesía do Grupo Poético Bilbao. Para iso, analízanse diversos poemas de varios dos seus membros co gallo de entender cal é a súa visión sobre o espazo urbano, ás veces no confronto co espazo rural.
\end{abstract}

Palabras chave: cidade, espazo, Grupo Poético Bilbao.

\begin{abstract}
This paper analyses the semantic diversity and plurality of the concept of «city» in the poetry of the so-called Grupo Bilbao. For this purpose, several poems were chosen in order to allow for the understanding each individual vision of the urban space, sometimes contrasted with the rural one
\end{abstract}

Key words: city, space, poetic Bilbao Group

Cando en outubro de 1998 Xavier Frías me pediu que escribise o limiar da antoloxía nomeada Comercial, comecei desta maneira

(..) Para min supón unha ledicia este encargo porque falar destes poemas é coñecer máis a poesía deste grupo de poetas que desde Madrid escriben en lingua galega. Tamén supón un compromiso e un reto, xa que a miña presentación debería resumi-la historia do grupo e dar ó lector unha idea aproximada do significado destes poemas. Non sei se conseguirei chegar ás metas propostas, máis quero manifestar que nesta presentación poño toda a miña inquedanza e ilusión (Comercial 1998: 9).

Desde entón ata hoxe pasaron moitas cousas, e os nosos poetas seguiron coas súas creacións. Eu, desde as miñas aulas, e co meu compromiso de difundir a cultura galega, presentaba aos estudantes as creacións destes poetas e timidamente facíalles suxerimentos; así saíron estudos que foron publicándose na Revista de Estudios Gallegos, Madrygal editada pola Universidade Complu- 
tense que eu dirixo, como o estudo que fixo María Martínez Xoubanova sobre o simbolismo na poesía de Fermín Bouza Álvarez (Madrygal 2001, 4: 77-88) ou o de Verónica Palomares sobre a poética amorosa de Vicente Araguas (Madrygal 2005, 8: 97-105) ou o estudo de Begoña Regueiro sobre a poesía da experiencia de Manuel Pereira Valcárcel (Madrygal 2006, 9: 103-113), as cales (Verónica e máis Begoña) actualizan cos seus estudos as poéticas de Vicente Araguas e de Manuel Pereira. Pola súa banda, André Pociña fala neste anexo da creación de Xavier Frías. Luís Luna, tamén alumno no pasado, aproxímase á colección Roibén, na que publican os poetas do Grupo Bilbao, ás veces itinerantes e cambiantes, pero sempre cos fundadores do grupo: Fermín Bouza (agora algo máis distanciado), Vicente Araguas, Xavier Frías e Manuel Pereira.

No libriño chamado Comercial (1998) estaban ademais dos clásicos, dos consagrados, Claudio Pato e José Manuel Outeiro. Manuel Pereira no mesmo ano, 1998, publica Todo morte, un poemario estremecedor no que o poeta se reconcilia coa morte:

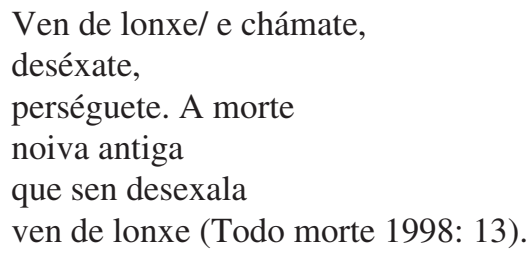

Así, os poetas do Grupo Bilbao foron medrando e, co paso do tempo, os poetas novos forneceron a súa poesía para publicaren na colección $O$ Roibén, da que fala Luís Luna, como poeta do Grupo Bilbao. O ano 2000 foi un ano de moita actividade dos poetas máis novos. Xosé Galán, Rafa Yáñez e, o prolífico, Xavier Frías; Susana González e Victoria Veiguela (daquela alumnas miñas) debutan co poemario Simbiose, cuo limiar é de Manuel Pereira; o mesmo que Luís Luna e Óscar Curieses co libriño Hidroemas presentado por Ana Acuña, quen salienta a riqueza simbólica do mesmo. En 2001 publican Calros Solla e, de novo, Rafa Yáñez. Outros poemarios de Xavier Frías, Victoria Veiguela, Luís Luna e Óscar Curieses continúan a súa andaina no 2002 xunto a unha tradución dos Poemas Póstumos de Mihai Eminescu feita por Inma Pérez Rocha. Despois sairá do prelo Alcálima, nacida no 2004 da man de Xavier Frías, Rafa Yáñez e, posteriormente, Luís Luna.

No ano 2010 publícase outra antoloxía nomeada Marés nos pousos do café. Mostra de poetas de expresión galega en Madrid (2010), (Pontevedra: El taller del poeta), cuxo responsable da edición é Xavier Frías. Esta vez o limiar foi da autoría de Asunción Canal Covelo, quen tería que participar neste «Día das Letras Galegas» pero lle foi imposible. Sentimos moito a súa ausencia igual que escoitamos a Xesús Alonso Montero lido por Ana Acuña na Homenaxe a Isaac Díaz Pardo no «Espazo das Linguas Ibéricas» e sentimos a súa falta, tamén, na Facultade de Filoloxía da UCM onde tiñamos previsto que falase de Celso Emilio Ferreiro. Pero, a pesar das ausencias, o Día das Letras Galegas deste ano 2012 rematou coa presentación da nova antoloxía poética do Grupo Bilbao, esta vez coa recuperación da voz de Victoria Veiguela. 
Nesta liña desexo destacar a modernidade do Grupo Bilbao desde a poética do lugar, da cidade, grande ou pequena, porque os lugares forman parte da nosa vida e polo tanto os espazos vitais ten unha pluralidade semántica nos nosos poetas. Pero non soamente son as cidades, tamén poden ser outros espazos, como a casa, por exemplo, aos que faremos referencia pola importancia dos mesmos nas diferentes poéticas deste grupo de poetas xa consolidado.

1. A cidade de Madrid, cobra presenza no poema Antonio Machado saíndo d'El Comercial (outubro, 1936) que Vicente Araguas dedica a Rafael Yáñez e que se publica na citada antoloxía Marés nos pousos do café (2010):

\title{
Invisible avión moscardonea
}

A.M.

\author{
Souberas como brilla \\ esta lúa de outono \\ (o sol tiña na tarde \\ maneiras de limón). \\ Pensábate coas forzas \\ que xa non teño, enviso \\ en tempos violentos; \\ a roda desta porta \\ que se vira pousona, \\ os folgos que escasean, \\ o café moi cativo, \\ a botella no mar. \\ Camiño cando ti \\ por rúas solitarias \\ (a xente en horas bélicas \\ agacha o seu terror). \\ Andando amodiño \\ volvendo para a casa, \\ home náufrago e só, \\ a lúa, golpe branco. \\ Por riba dos tellados \\ un avión salouca, \\ maquinando puntadas \\ neste Madrid febril. \\ Ti, soño imposible, \\ onde queira que esteas, \\ e o meu poema area \\ e botella no mar.
}

A poética de Vicente Araguas está chea de contrastes, de luz, de olor, do perigo que se percibe nese camiñar lento, nesa volta do náufrago solitario cara a casa, o espazo protector, nesa cidade, Madrid, chea de febre perigosa, e, como sempre no imaxinario araguaniano, ese $\mathrm{Ti}$, que abre a posibilidade da esperanza, co poema na botella que leva a mensaxe amorosa no mar. 
2. Xavier Frías pola súa banda ten un poema que se chama «Madrid» na mesma antoloxía (Marés nos pousos do café 2010: 38) no que a chuvia toma protagonismo nese espazo de experiencias opostas e que a chuvia borra da memoria, do recordo:

\author{
MADRID \\ Finalmente \\ choveu, \\ choveu como nunca \\ ten chovido. \\ Choveu indolentemente \\ até varrer \\ tanto silencio bébedo de ausencias, \\ choveu polas rúas \\ que percorren brazos mordidos \\ e portos exiliados \\ até as ramplas da memoria \\ Choveu en Madrid \\ amando e odiando \\ morrendo e resucitando \\ soletreando e disparando \\ entre estatuas \\ xa descaradas \\ a procuraren pracer \\ na memoria dos que xa nin as recordan. \\ Choveume \\ no rostro \\ apagándome \\ talvez \\ sen anestesias
}

O amor, o odio, a morte, a vida xa sen a dor que, ás veces, leva o recordo, a memoria. Un poema cheo de vida, de dor e de desesperanza nesa cidade na que todo pasa. A cidade, como espazo vital no que a chama da vida tamén se apaga, quizá, porque a batalla da vida xa non ten chama. Cabe destacar a importancia dos xerundios que impregnan ao poema dun movemento imparable de sensacións que asolaga a sensibilidade do lector.

3. Manuel Pereira preséntanos dous espazos fundamentais: Ouzande, a aldea de orixe e Madrid, cidade de chegada, onde ten lugar a súa viaxe iniciática na aventura existencial. De Ouzande ten que saír, dicir adeus á natureza, ao propio e á tranquilidade:

Haberá que dicir adeus.

Partir

vencidos de seráns

Adeus

a quen nos quixo, 


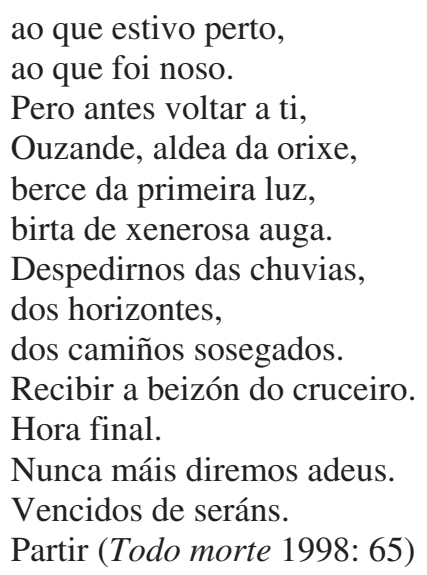

E, despois, desta despedida, deste adeus ás raíces, o poema nomeado Plano Xeral (Tatuaxes 2011: 15) fala de Madrid, a cidade onde se fai toda a súa vida despois da nenez. A chegada á estación do tren e de eles, os estudos, os amigos, o amor, a voda e a filla. Toda unha vida feita nesa cidade, pero sen esquecer Ouzande.

\section{PLANO XERAL}

Madrid, xaneiro de 1974.

Estación do Norte, Príncipe Pío.

O tren expreso procedente da Coruña e Vigo, ao que subiramos en Santiago, chegara ao destino. Tamén nosoutros.

Meu irmán e mais eu agardabamos un taxi.

Colexio Maior, pisos de estudantes, amizade. Xuño e setembro.

Noiva, emprego, voda.

Domicilios de clima suave nos que María medrou.

Ouzande na memoria, constantemente.

E segue a combustión sucesiva dos retratos. Desta maneira en Tatuaxes hai un número importante de imaxes dese espazo onde a esperanza existe e a vida segue. Unha cidade na que non só vive o poeta senón que a cidade tamén vive en Manuel Pereira.

4. Rafa Yáñez, pola súa parte, vive nas cidades polas que viaxa e escribe o que fixo nelas, ou as súas impresións para retelas con el; unha estratexia para que non se perdan, para que a escrita as manteña e non se esquezan. A maioría son cidades visitadas con alguén que forma parte da vida do poeta, unha viaxe xa feita: 
1. Dublín na memoria

había un paraugas vello

cravado na area

e unha rosa murcha

entre as súas variñas

brétema máis aló

pequenas raiolas

e a caída vertical

do teu ollar atlántico (Marés: 61)

Esta viaxe por Dublín, Lisboa, Marrákech queda como testemuño do vivido. No seu último poemario, o poeta viaxa a súa terra, a Terra Chá, para nos dicir que sen ela non podería ser quen é, e por iso a personifica, a terra como a muller da súa vida:

A Chá ten sabor a augardente

cun regusto de dorna baleira.

É unha muller con padal acedo, e follas secas en outono.

É perfume de choiva e voos de estorniños.

A Chá ten voz operística con ecos de piano-jazz.

É un saúdo

á xaneira,

é o jet lag alcohólico

e morno

ao lembrala de lonxe.

A Chá ten ollos

de impresionismo

na paisaxe sensual.

É un cartel de pop art

afoutado nun despacho senlleiro

Sona a abrente pardo

e agocha un segredo

de merlo mouro.

A Chá ten tacto de seda a carón da nube única no ceo da mañá. (Da Chá ao lonxe: 55) 
A voz poética ten saudades da terra propia e, desde a distancia, describe a terra como muller imposible de esquecer e sempre añorada. O imaxinario de Rafa Yáñez sae para fóra e desde os sentidos describe o obxecto do desexo: A Terra Chá, espazo imprescindible para a súa existencia.

5. Begoña Regueiro, pola súa banda, ten un poema que fala da necesidade do obrigado regreso ao espazo íntimo, propio:

Todos precisamos dunha patria á que regresar

Cando a vida pesa demasiado

Un espacio propio, íntimo,

Onde cada recuncho nos coñeza, e garde

Algún refugallo dos soños esquecidos.

Hai unha praia branca,

no norte,

á que vai o vento a descansar.

Hai unha duna suave,

No oeste,

Onde as buguinas dormen

e as estrelas de mar se espreguizan.

Cando descubras que rompeu a miña alma,

que xa non puiden máis,

búscame alí, entre as areas.

No resplandor fugaz dalgunha cuncha

deixareiche o recordo dos meus ollos.

Para que sempre me sintas ao teu lado.

Para que nunca te asolague a soidade. ( Mares: 57)

Begoña, con este regreso, formula a necesidade de ter un espazo propio e que o ser amado cando a busque saiba onde atopala. A dualidade vida/morte reflíctese nesta xeografía poética coa que Begoña Regueiro se identifica e permanece.

6. Luís Luna enfróntase co eu do poeta, coa loita interior da creación poética, de novo o espazo interior que só consegue exteriorizarse coa palabra poética:

Esa é a súa casa, limiar dunha ferruxe.

Un muro só a esboroar.

Parapeto dos egos

En loita

polo corpo.

Unha vez que o poeta vence chega á exteriorización da palabra:

Dicir aínda así, na liña branca 
No gume dun coitelo.

Aínda é a palabra.

$\mathrm{O}$ útero do anxo.

A cesación

do ruído ( Marés: 47)

Desta maneira, as cidades e os espazos maniféstanse desde unha pluralidade semántica que corresponde á diversidade das poéticas dos poetas do Grupo Bilbao.

\section{BIBLIOGRAFÍA DE REFERENCIA:}

AA.VV. (1998): Comercial. Poesía galega en Madrid. Colección O Roibén. Neda (A Coruña), Edicións Río Xuvia.

AA. VV. (2010): Marés nos pousos do café. Mostra de poetas de expresión galega en Madrid. Pontevedra, El taller del poeta.

Pereira Valcárcel, M. (1998): Todo morte. Colección O Roibén. Neda, A Coruña, Edicións Río Xuvia.

Pereira Valcárcel, M. (2011): Tatuaxes, Santiago de Compostela, Follas Novas Edicións.

Yáñez, R. (2011): Da Chá ao lonxe, Lugo, Instituto de Estudios Chairegos de Vilalba. 